\title{
Qualidade de sementes de Helianthus annuus L. em função da adubação fosfatada e da localização na inflorescência
}

\author{
Quality of Helianthus annuus L. seeds as a function of phosphate and location in the inflorescence
}

\author{
Humberto Pereira da Silva ${ }^{\mathrm{I}}$ Delacyr da Silva Brandão Junior ${ }^{\mathrm{II}}$ José Maria Gomes Neves ${ }^{\mathrm{III}}$ \\ Regynaldo Arruda Sampaio ${ }^{\mathrm{II}}$ Rômulo Fredson Duarte ${ }^{\mathrm{IV}}$ Ariadne Santos Oliveira $^{\mathrm{V}}$
}

RESUMO

Nos últimos anos, a expansão da cultura do girassol promoveu uma busca por material genético mais competitivo, além de sementes com uma máxima qualidade física, fisiológica e sanitária. No campo, a época de colheita e a nutrição das plantas são de fundamental importância na expressão dessas qualidades. Com isso, objetivou-se, com este trabalho, avaliar a qualidade física e fisiológica das sementes de girassol submetidas a diferentes doses de fósforo e suas localizações dentro da inflorescência. $O$ delineamento experimental foi em blocos casualizados em esquema fatorial (3x2), sendo o primeiro fator a localização da semente na inflorescência (periferia, meio e centro) e, o segundo, doses de fósforo (zero e $70 \mathrm{~kg} \mathrm{ha}^{-1}$ de super-simples), sendo sua aplicação realizada durante a implantação da cultura. As sementes foram submetidas à determinação do teor de água, peso de mil sementes, peso das sementes por localização na inflorescência e a testes de germinação e vigor (primeira contagem e índice de velocidade de germinação). A adubação fosfatada proporciona aumento na qualidade física e fisiológica das sementes de girassol. A região da periferia junto com o meio contribui em maior parte para a obtenção de uma melhor qualidade física e fisiológica das sementes de girassol. A qualidade física é afetada pela localização das sementes na inflorescência, cujas mais pesadas se encontram na periferia, seguidas das do meio e tendo o centro com as sementes mais leves.

Palavras chave: girassol, capítulo, qualidade de sementes.

\begin{abstract}
In recent years, the expansion of sunflower promoted a search for genetic material more competitive, and for seeds with a maximum physical, physiological and health quality. In the field, harvesting time and plant nutrition are essential in the expression of these qualities. With this objective, this research aimed to evaluate the physical and physiological quality of sunflower seeds under different phosphorus levels and locations within the same inflorescence. The experimental design was randomized blocks in factorial (3x2), being the first factor, the location of the seed in the inflorescence (outside, middle and center) and the second phosphorus levels (zero and to $70 \mathrm{~kg} \mathrm{ha}^{-1}$ super-simple). Its application was performed during the culture deployment. Seeds were subjected to the moisture content determination, thousand seed weight, seed weight per inflorescence location in germination and vigor (first count and index of germination rate). Phosphorus fertilization allowed an increase in physical and physiological quality of sunflower seeds. The region along the periphery with the environment contributes in most to obtain a better physical and physiological quality of sunflower seeds. The physical quality is affected by the location of seeds in inflorescences, which are heavier in the periphery, followed by middle and having the center with lighter seeds.
\end{abstract}

Key words: sunflower, chapter, seed quality.

'Departamento de Fitotecnia, Setor de Sementes, Universidade Federal de Lavras (UFLA), 37200-000, Lavras, MG, Brasil. E-mail: humbertofu@yahoo.com.br. Autor para correspondência.

IIDepartamento de Fitotecnia do Instituto de Ciências Agrárias, Universidade Federal de Minas Gerais (UFMG), Montes Claros, MG, Brasil.

IIIDepartamento de Fitotecnia, Universidade Federal de Viçosa (UFV), Lavras, MG, Brasil.

IV Departamento de Ciência do Solo, UFLA, 37200-000, Lavras, MG, Brasil.

'Departamento de Produção Vegetal, Universidade Federal dos Vales do Jequitinhonha e Mucuri (UFVJM), Diamantina, MG, Brasil. 


\section{INTRODUÇÃO}

O girassol figura como a quinta cultura oleaginosa em produção de grãos, antecedido pelas culturas da soja, do algodão, da colza e do amendoim. De 2006 a 2010, houve um crescimento médio de $2,7 \%$, o que a possibilitou tornar-se a quarta oleaginosa em produção de óleo do mundo (USDA, 2010). A demanda mundial por óleo de girassol cresce em média, $1,8 \%$ ao ano. Pelas estimativas realizadas pelo USDA, no mês de abril/2010, a nível mundial, poderá ocorrer um acréscimo na produção dos grãos em torno de $10,51 \%$, farelo em 6,75\% e óleo de 6,96\%. No Brasil, houve um crescimento da demanda por grãos destinados à extração do óleo para alimentação e para a produção de bicombustível, no entanto, a produção interna ainda não acompanha esses avanços.

Essa expansão da cultura causou grande influência no mercado de sementes, uma vez que a demanda aumentou significativamente e as exigências são cada vez maiores por sementes de qualidade. Durante a produção de sementes, a qualidade pode ser afetada desde a fase de implantação, condução e colheita da lavoura. Um dos fatores de maior destaque na produção que influencia diretamente na qualidade das sementes de girassol é a desuniformidade de maturação das sementes.

A maturação das sementes de girassol é bastante complexa, pois em uma mesma época podem ocorrer diferenças no grau de maturação entre capítulos de diferentes plantas. Para ANDERSON (1975), a antese no girassol ocorre de forma desigual no capítulo, da margem para o centro, de modo que as sementes de uma mesma planta se encontram em diferentes estádios de desenvolvimento, o que dificulta a realização da colheita no ponto de maturidade fisiológica, comprometendo assim a qualidade das sementes, pois para que um lote contenha boa qualidade é imprescindível que a colheita ocorra o mais próximo da maturidade fisiológica das sementes (CARVALHO \& NAKAGAWA, 2000).

Outro fator que influencia na qualidade das sementes é a nutrição adequada das plantas e a cultura do girassol possui exigências nutricionais superiores as de outras culturas como trigo, sorgo e milho, requerendo quantidades maiores de macronutrientes (VIGIL, 1995). Para o girassol, o período em que ocorre uma maior taxa de absorção de nutrientes é a fase imediatamente após a formação do botão floral até o final do florescimento (CASTRO et al., 1997). Essas exigências aumentam ainda mais em se tratando de campos de produção de sementes, uma vez que a formação do embrião e dos tecidos de reserva, assim como a composição química, pode ser prejudicada pela disponibilidade de nutrientes para as plantas, reduzindo não só a produtividade, mas também a qualidade das sementes (CARVALHO \& NAKAGAWA, 2000). Dentre os aspectos que compõem a qualidade das sementes, o vigor das plântulas está diretamente envolvido com a nutrição das plantas, por estar diretamente relacionado com a composição química das sementes (KEISER\& MULLEN, 1993).

Dos macronutrientes, o fósforo geralmente é um elemento limitante da produção agrícola nas regiões tropicais e subtropicais, devido aos seus baixos teores no solo. Para elevar os níveis de fósforo no solo, a correção com a adubação fosfatada se torna uma prática adotada constantemente (MINHONI et al., 1991). O fósforo atua durante o florescimento e frutificação das plantas, promovendo desenvolvimento do sistema radicular e incrementando a produção (RAIJ, 1991). Segundo SANCHEZ (2007), a deficiência em fósforo resulta em plantas menos desenvolvidas e prejudica o enchimento dos aquênios, o que leva a uma redução da produtividade e teor de óleo. Mesmo sendo um dos nutrientes que proporciona maior desempenho nas culturas, na literatura, são poucos os trabalhos que enfatizam a importância do fósforo na qualidade das sementes de girassol.

Em detrimento desses problemas e devido à carência dessas informações para a cultura, objetivouse com este trabalho avaliar a qualidade física e fisiológica das sementes de girassol submetidas a diferentes doses de fósforo e suas localizações dentro da inflorescência.

\section{MATERIAL E MÉTODOS}

O trabalho foi realizado em área experimental do Instituto de Ciências Agrárias da Universidade Federal de Minas Gerais, na cidade de Montes Claro MG. A extensão da área era de oito hectares historicamente cultivados com milho e feijão, em sistema de rotação. O material utilizado na pesquisa foi a variedade de girassol EMBRAPA 122.

A semeadura foi realizada em março de 2009, sob sistema de irrigação por aspersão, com uma densidade de plantio de 45 mil plantas por hectare. Com base na análise de solo, não foi necessário proceder à correção $\left(\mathrm{SB}=7,30 \mathrm{Cmol}_{\mathrm{c}} \mathrm{dm}^{-3} ; \mathrm{V}=74,0 \% \mathrm{e}\right.$ $\mathrm{pH}=6,2$ ), exceto para o boro e, para todos os tratamentos, foram aplicados $2 \mathrm{~kg} \mathrm{ha}^{-1}$ na forma de acido bórico via adubação foliar. Os demais tratos culturais foram os usualmente empregados para a cultura do girassol. As parcelas experimentais foram compostas por quatro linhas com 6m de comprimento, com uma área total de $19,2 \mathrm{~m}^{2} \mathrm{e}$ a área útil, foram avaliadas as duas linhas centrais de cada parcela, desprezando-se $0,5 \mathrm{~m}$ de cada extremidade.

Os tratamentos foram dispostos em blocos casualizados em um arranjo fatorial ( $3 \times 2)$, sendo o primeiro fator com três diferentes localizações das 
sementes dentro da inflorescência (periferia, meio e centro), as quais foram divididas com o uso de um paquímetro, a partir do diâmetro total das inflorescências. Além disso, foram adicionadas duas doses de fósforo, sendo que a dose zero foi representada pela fertilidade natural do solo que, de acordo com a análise de solo era de $2,5 \mathrm{mg} \mathrm{dm}^{-3} \mathrm{e} 70 \mathrm{~kg}$ $\mathrm{ha}^{-1}$, na forma de super fosfato simples, aplicado durante a implantação da cultura.

A colheita foi realizada manualmente quando as inflorescências se encontravam completamente secas. Em seguida, as inflorescências foram levadas ao Laboratório de Análise de Sementes do Instituto de Ciências Agrárias da Universidade Federal de Minas Gerais (LAS ICA/UFMG), onde os aquênios foram retirados de forma manual e homogeneizados de acordo com a localização (periferia, meio e centro). As sementes foram pesadas por região para a determinação do peso de sementes por localização na inflorescência e os resultados expressos em gramas.

Em seguida, as sementes foram avaliadas quanto à qualidade física e fisiológica, seguindo as prescrições contidas nas Regras para Análise de Sementes (BRASIL, 2009). A qualidade física foi determinada pelo teor de água, avaliado pelo método de estufa a $105 \pm 3^{\circ} \mathrm{C}$ durante 24 horas, com duas subamostras de quatro gramas para cada tratamento e os resultados foram expressos em percentagem. Avaliou-se também a massa de mil sementes com oito subamostras de 100 sementes foram contadas e pesadas e os resultados foram expressos em gramas (g).

A qualidade fisiológica foi avaliada pelo teste de germinação. Para tanto, foram utilizadas quatro subamostras de 50 sementes, distribuídas em folhas de papel Germitest ${ }^{\circledast}$ no sistema rolo, umedecidas com água destilada, na quantidade equivalente a 2,5 vezes o peso do substrato seco. Em seguida, esses rolos foram colocados em um germinador tipo Mandelsdorf sob regime de luz natural, regulado a temperatura constante de $25^{\circ} \mathrm{C}$. As avaliações foram realizadas computando-se o número de plântulas normais no quarto dia do início do teste para a primeira contagem de germinação e no décimo dia para a germinação, os resultados foram expressos em porcentagem e índice de velocidade de germinação, realizado conjuntamente com o teste de germinação, por meio de anotações diárias do número de sementes germinadas de acordo com MAGUIRE (1962).

Com a massa de mil sementes e peso de sementes da inflorescência, estimou-se o número médio de sementes e, com base nas demais avaliações, foi calculada a contribuição média de cada local na constituição total das inflorescências.

Os dados obtidos foram submetidos à análise de variância, utilizando-se o programa SAEG, e as médias comparadas pelo teste Scott Knott a 5\% de probabilidade. Os dados do número médio de sementes e a contribuição média de cada local na constituição total das inflorescências não foram submetidos a análises estatísticas.

\section{RESULTADOS E DISCUSSÃO}

A umidade das sementes provenientes de plantas que receberam $70 \mathrm{~kg} \mathrm{ha}^{-1}$ de fósforo variou de 8,$58 ; 8,16$ e $8,06 \%$ para aquelas localizadas na periferia, no meio e no centro, respectivamente, enquanto, para as sementes das plantas que não receberam o fósforo, a variação foi de 9,2; 9,21 e 8,95\% para as mesmas localizações.

Em nenhuma das variáveis foi observado efeito significativo da interação entre as doses de fósforo e a localização das sementes na inflorescência. Verificou-se efeito significativo das doses isoladas de fósforo ao nível de $5 \%$ de probabilidade para os testes de germinação, primeira contagem e' peso de mil sementes (Tabela 1). Esses resultados destacam a importância do uso do fósforo na produção de sementes de girassol por promover incrementos significativos na qualidade física e fisiológica das sementes.

A aplicação de fósforo no solo, provavelmente pode ter elevado seus teores nas sementes, conferindo a estas uma maior qualidade fisiológica. Em outras culturas, sabe-se que o incremento da adubação fosfatada aumenta o teor de fósforo nas sementes, principalmente na forma de fitatos, sendo que, em condições normais de disponibilidade de fósforo, o fitato representa mais de 80\% do fósforo total (BUERKERT et al., 1998; MÖLLERS et al., 1999). Segundo SACHS et al. (2006), as sementes de girassol são ricas em alguns fotoquímicos, tendo como principais os fitatos, ácido clorogênico e fitoesteróis. Dentre esses, os fitatos são reservas secundárias de fósforo usadas subsidiariamente nas funções vitais da semente, principalmente na germinação.

Esses resultados estão de acordo como os de GOYA et al. (1990) ao avaliarem o efeito da adubação fosfatada na qualidade de sementes de girassol IACAnhandy e evidenciarem aumento no seu vigor com a elevação das doses de fósforo. Os efeitos benéficos do fósforo na qualidade fisiológica das sementes também foram observados por NAKAGAWA et al. (1993) em amendoim; GUERRA et al. (2006) em soja e ZUCARELI et al. (2006) em feijão.

Para a localização das sementes na inflorescência (periferia, meio e centro), também houve efeito isolado na avaliação da massa de mil sementes e das sementes em cada local. Quanto à porcentagem de germinação, primeira contagem e índice de velocidade de germinação, não se constataram diferenças estatísticas significativas (Tabela 2). 
Tabela 1 - Massa de mil sementes (MMS) e massa de sementes da inflorescência (MSI), porcentagem de germinação (GER), primeira contagem (PC) e índice de velocidade de germinação (IVG) das sementes de girassol BR-122, submetidas à aplicação de fósforo. Instituto de Ciências Agrárias/UFMG, Montes Claros-MG, 2011.

\begin{tabular}{llcccc}
\hline Adubação & MMS $(\mathrm{g})$ & MSI $(\mathrm{g})$ & GER $(\%)$ & PC (\%) & IVG \\
\hline Com fósforo & $46,11 \mathrm{~A}$ & 11,23 & $60,0 \mathrm{~A}$ & $50,0 \mathrm{~A}$ & 4,09 \\
Sem fósforo & $41,8 \mathrm{~B}$ & 10,73 & $42,0 \mathrm{~B}$ & $29,0 \mathrm{~B}$ & 3,66 \\
CV $(\%)$ & 4,02 & 33,07 & 16,08 & 19,24 & 26,56 \\
\hline
\end{tabular}

Médias seguidas pela mesma letra na coluna não diferem entre si pelo teste Scott Knott, em nível de 5\% de probabilidade.

Com relação à massa de mil sementes e das sementes de cada local da inflorescência, verificou-se que aquelas localizadas na periferia foram as mais pesadas, em seguida as do meio e as do centro da inflorescência com as sementes mais leves. Esses resultados corroboram os de BAYDAR \& ERBA (2005), que, além de observarem maiores pesos nas sementes da periferia, identificaram estas como sendo ricas em ácido linoléico e no teor de tocoferol. Para MUNSHI et al. (2003), a má formação das sementes do centro provavelmente está associada a inadequadas conexões vasculares que restringem o abastecimento de água e assimilados.

Essa variação pode ser atribuída a vários fatores, dentre eles as diferenças ocorridas na maturação das sementes e a distribuição de fotoassimilados para elas, já que as sementes na inflorescência se organizam em uma espiral que amadurecem progressivamente da periferia para o centro, cuja completa abertura das flores ocorre dentro de 10 a 15 dias (MUNSHI et al., 2003). De acordo com STEER et al. (1988), as sementes do centro alcançaram desenvolvimento melhor quando a competição com as outras localizações da inflorescência foi reduzida. As variações das sementes no decorrer da inflorescência estão relacionadas também com o tempo para o seu enchimento na relação fonte/dreno possibilitando maior suprimento de fotoassimilados e água (ALKIO et al., 2003).

O centro das inflorescências caracterizouse por haver uma grande quantidade de sementes chochas e restos florais que tendem a prejudicar a sua qualidade física, pois eleva a quantidade de impurezas e dificulta as etapas do beneficiamento. MAEDA et al. (1987) verificaram que a quantidade de sementes chochas foi bastante elevada, notadamente nas posições do centro e no meio, com 99,4 e 92,0\%, respectivamente; ainda relataram que o teor de óleo foi muito baixo no centro, com valores inferiores $(2,2 \%)$ aos das demais localizações da inflorescência.

$\mathrm{Na}$ ocasião da colheita, realizada após a maturidade fisiológica das sementes, quando as inflorescências já se encontravam totalmente secas, a germinação e o vigor das sementes de girassol das diferentes localizações não se diferenciaram ao longo da inflorescência (Tabela 2). Resultados semelhantes foram obtidos por MAEDA et al. (1987) quando avaliaram o estádio de maturação e a qualidade de sementes de girassol, momento em que observaram que a germinação e o teor de óleo independem da localização da semente na inflorescência, quando a colheita é realizada na maturidade fisiológica.

Com relação à contribuição das localizações das sementes na inflorescência, para a variável massa de mil sementes e massa total das sementes, juntas as localizações periferia e meio contribuíram com 75 e $81 \%$ do total da inflorescência respectivamente; a região periférica participou com 25 e 19\%. Com relação à germinação, à primeira contagem, ao índice de velocidade de germinação e ao número de sementes na região periférica, juntamente com o meio, a contribuição foi de $68,0 \% ; 69,0 \% ; 76,0 \%$ e $74 \%$ do total (Tabela 3 ).

Tabela 2 - Massa de mil sementes (MMS), massa das sementes na inflorescência (MSI), porcentagem de germinação (GER), primeira contagem (PC) e índice de velocidade de germinação (IVG) das sementes de girassol BR-122, originadas das diferentes posições na inflorescência. Instituto de Ciências Agrárias/UFMG, Montes Claros-MG, 2011.

\begin{tabular}{lllccc}
\hline $\begin{array}{l}\text { Posições da semente na } \\
\text { inflorescência }\end{array}$ & MMS (g) & MSI (g) & GER (\%) & PC (\%) & IVG \\
\hline Centro & $33,00 \mathrm{C}$ & $6,29 \mathrm{~B}$ & 48,50 & 36,00 & 5,37 \\
Meio & $45,30 \mathrm{~B}$ & $11,64 \mathrm{~A}$ & 51,00 & 40,50 & 7,05 \\
Periferia & $53,56 \mathrm{~A}$ & $15,00 \mathrm{~A}$ & 53,00 & 41,00 & 10,28 \\
CV $(\%)$ & 4,02 & 33,07 & 16,08 & 19,24 & 26,56 \\
\hline
\end{tabular}

Médias seguidas pela mesma letra nas colunas não diferem entre si, pelo teste Scott - Knott, em nível de 5\% de probabilidade.

Ciência Rural, v.41, n.7, jul, 2011. 
Tabela 3 - Contribuição média de cada localização da inflorescência em porcentagem da massa de mil sementes (MMS), massa das sementes na inflorescência (MSI), porcentagem de germinação (GER), primeira contagem (PC) índice de velocidade de germinação (IVG) e número de sementes (NS) de girassol variedade BR-122. Instituto de Ciências Agrárias/UFMG, Montes Claros-MG, 2011.

\begin{tabular}{lcccccc}
\hline Posições da semente na inflorescência & MMS $(\%)$ & MSI $(\%)$ & GER $(\%)$ & PC $(\%)$ & IVG $(\%)$ & NS \\
\hline Centro & 25,0 & 19,0 & 32,0 & 31,0 & 24,0 & 191,0 \\
Meio & 34,0 & 35,0 & 33,0 & 34,0 & 31,0 & 257,0 \\
Periferia & 41,0 & 46,0 & 35,0 & 35,0 & 45,0 & 280,0 \\
\hline
\end{tabular}

Esses resultados destacam eventuais cuidados com a condução da cultura, quando as sementes localizadas na periferia e no meio das inflorescências estiverem sendo formadas, principalmente para problemas decorrentes da ação de pássaros, já que causam grande estrago, principalmente na região da periferia das inflorescências.

\section{CONCLUSÃO}

A adubação fosfatada proporciona aumento na qualidade física e fisiológica das sementes de girassol.

A região da periferia junto com o meio contribui em maior parte para a obtenção de uma melhor qualidade física e fisiológica das sementes de girassol.

A qualidade física é afetada pela localização das sementes na inflorescência, cujas mais pesadas se encontram na periferia, seguidas das do meio e tendo o centro com as sementes mais leves.

\section{REFERÊNCIAS}

ALKIO, M. et al. Effect of source-sink ratio on seed set and filling in sunflower (Helianthus annuus L.). Plant, Cell and Environment, Oxford, v.26, n.10, p.1609-1619, 2003. Disponível em: <http://onlinelibrary.wiley.com/doi/10.1046/ j.0016-8025.2003.01077.x/pdf>. Acesso em: 25 jan. 2011. doi: 10.1046/j.0016-8025.2003.01077.x.

ANDERSON, W.K. Maturation of sunflower. Australian Journal of Experimental Agriculture and Animal Husbandry, v.15, p.833-838, 1975. Disponível em: <http:// www.publish.csiro.au/paper/EA9750833.htm>. Acesso em: 12 out. 2009. doi: 10.1071/EA9750833.

BAYDAR, H.; ERBAS, S. Influence of seed development and seed position on oil, fatty acids and total tocopherol contents in sunflower (Helianthus annuus L.). Turkish Journal of Agriculture and Forestry, v.29, p.179-186, 2005. Disponível em: <http://journals.tubitak.gov.tr/agriculture/issues/tar-05-293/tar-29-3-4-0406-3.pdf>. Acesso em: 27 ago. 2009.

BRASIL. Ministério da Agricultura e Reforma Agrária. Regras para análise de sementes. Brasília: SNAD/DNDV/CLAV, 2009. 395p.

BUERKERT, A. et al. Phosphorus application effects the nutritional quality of millet grain in the Sahel. Field Crops Research, v.57, p.223-235, 1998. Disponível em: <http://www.sciencedirect.com/ science?_ob=ArticleURL\&_udi=B6T6M-3 T6RX6K
7\&_user=10\&_coverDate $=05 \% 2 \mathrm{~F} 29 \% 2 \mathrm{~F} 1998 \&$ rdoc $=1 \& \_\mathrm{fmt}=$ high\&_orig=search\&_sort=d\&_docanchor $=\& v i e w=c \& \_s e a r c h S t r$ $\mathrm{Id}=1259118001 \& \_$rerunOrigin $=$google\&_acct $=\mathrm{C} 000050221 \& \_$version $=1$ \&_urlVersion=0\&_userid=10\&md5=bb5a6039b15227610blb0c0bcf003ff7 > . Acesso em: 07 jun. 2009. doi:10.1016/S0378-4290(97)00136-6.

CARVALHO, N.M.; NAKAGAWA, J. Sementes: ciência, tecnologia e produção. 4.ed. Jaboticabal: FUNEP, 2000. 588p.

CASTRO, C. et al. Cultura do girassol. Londrina: EMBRAPA: CNPSo, 1997. 36p. (Circular Técnica, 13).

GOYA, P.G.R.; SADER, R. Efeito da adubação fosfatada na qualidade de sementes de girassol da CV. IAC-ANHANDY. Revista Brasileira de Sementes, v.12, p.17-27, 1990. Disponível em: <http://www.abrates.org.br/revista/artigos/1990/ v12n3/artigo02.pdf>. Acesso em: 21 nov. 2009.

GUERRA, C.A. et al. Qualidade fisiológica de sementes de soja em função da adubação com fósforo, molibdênio e cobalto. Acta Scientiarum Agronomy, v.28, p.91-97, 2006. Disponível em: <http://periodicos.uem.br/ojs/index.php/ActaSciAgron/ article/view/1678/1043>. Acesso em: 25 jul. 2009. doi: 10.4025/ actasciagron.v28i1.1678.

KEISER, J.R.; MULLEN, R.E. Calcium and relative humidity effects on soybean seed nutrition and seed quality. Crop Science, v.33, p.1345-1349, 1993. Disponível em: <http:// crop.scijournals.org/cgi/content/full/40/2/476>. Acesso em: 12 dez. 2009.

MAEDA, J.A. et al. Estádio de maturação e qualidade de sementes de girassol. Bragantia, v.46, p.35-44, 1987. Disponível em: <http://www.iac.sp.gov.br/bragantia/volume/ 4601/460105.pdf>. Acesso em: 09 out. 2009. doi: 10.1590/ S0006-87051987000100005.

MAGUIRE, J.D. Speed of germination-aid in selection and evaluation for seedling emergence and vigor. Crop Science, v.1, p.176-177, 1962.

MINHONI, M.T.A. et al. Efeito de cinco tipos de matéria orgânica na solubilização microbiana de fosfato de rocha. Revista Brasileira de Ciência do Solo v.15, p.29-35, 1991.

MÖLLERS, C. et al. Influence of P-fertilizer on phytic acid content in seeds of Brassica napus L. and development of a NIRS calibration. In: INTERNATIONAL RAPESSED CONGRESS, 10., 1999, Canberra. Anais... Canberra: The Regional Institute, 1999. Disponível em: 〈http://regional.org.au/au/gcirc/1/357.htm〉. Acesso em: 15 nov. 2009.

MUNSHI, S.K. et al. Compositional changes in seeds influenced by their positions in different whorls of mature sunflower head. 
Journal of the Science of Food and Agriculture, v.83, p.16221626, 2003. Disponível em: <http://www3.interscience.wiley.com/ journal/106566295/abstract>. Acesso em: 29 nov. 2009. doi: $10.1002 /$ jsfa. 1603 .

NAKAGAWA, J. et al. Efeitos de fontes de fósforo e da calagem na produção do amendoim. Pesquisa Agropecuária Brasileira. v.28, p.421-31, 1993. Disponível em: <http://webnotes.sct.embrapa.br/ pab/pab.nsf/dfe523788c4d9ae503256508004f34ca/ edc7c5c4de8e9ef832568630066d0af/\$FILE/pab93_01_abr.pdf>. Acesso em: 31 out. 2009.

RAIJ, B.V. Fertilidade do solo e adubação. Piracicaba: Ceres/Potafos, 1991. 343p.

SACHS, L.G. et al. Efeito de NPK na produtividade e componentes químicos do girassol. Semina: Ciências Agrárias, v.27, p.533-546, 2006. Disponível em: <http:// www.uel.br/revistas/uel/index.php/semagrarias/article/view/2493/ 2118>. Acesso em: 10 maio, 2009.

STEER, B.T. et al. Dry matter, minerals and carbohydrates in the capitulum of sunflower (Helianthus annuus L), effects of competition between seeds and defoliation. Field Crops Research, v.18, p.71-
85, 1988. Disponível em: <http://www.sciencedirect.com/ science?_ob=ArticleURL\&_udi=B6T6M491574014\&_user=10\& coverDate $=02 \% 2 \mathrm{~F} 29 \% 2 \mathrm{~F} 1988 \& \_$rdoc $=1 \&$ ffmt=high $\& \_$orig $=$sear ch\&_sort $=\mathrm{d} \&$ docanchor $=\&$ view $=\mathrm{c} \&$ searchStrId $=1259159124 \&$ r erunOrigin $=$ google \&_acct $=$ C000050221\&_version $=1 \& \_u r l$ Version $=0 \&$ userid $=10 \& \mathrm{md} 5=175367 \mathrm{caa} 5 \mathrm{c} 6 \mathrm{abcba} 93 \mathrm{~b} 811 \mathrm{bfe} 8 \mathrm{~b} 5398 \mathrm{>}$. Acesso em: 15 nov. 2009. doi:10.1016/0378-4290(88)90060-3.

USDA - United States Department of Agriculture. Crop production. Disponível em: <http://usda.mannlib.cornell.edu/ usda/nass/CropProd/2010s/2010/CropProd-05-11-2010.pdf.> Acesso em: 10 fev. 2010.

VIGIL, M.F. Fertilization in dryland cropping systems: a brief overview Central Great Plains Research Station - USDAARS, 1995. Disponível em: 〈http://www.akron.ars.usda.gov〉. Acesso em: 12 dez. 2009.

ZUCARELI, C. et al. Adubação fosfatada, componentes de produção, produtividade e qualidade fisiológica em sementes de feijão. Revista Brasileira de Sementes, v.28, p.9-15, 2006. Disponível em: <http://www.scielo.br/pdf/rbs/v28n1/ a02v28n1.pdf>. Acesso em: 29 jul. 2009. doi: 10.1590/ S0101-31222006000100002. 